\title{
An intense SFE and SSC event in geomagnetic $H, Y$ and $Z$ fields at the Indian chain of observatories
}

\author{
R. G. Rastogi ${ }^{1 *}$, D. R. K. Rao $^{2}$, S. Alex ${ }^{2}$, B. M. Pathan ${ }^{2}$, T. S. Sastry ${ }^{3}$ \\ ${ }^{1}$ Department of Physics, Gujarat University, Ahmedabad 380 009, India \\ 2 Indian Institute of Geomagnetism, Mumbai 400 005, India \\ ${ }^{3}$ National Geophysical Research Institute, Hyderabad 500 007, India
}

Received: 3 June 1996 / Revised: 27 March 1997 / Accepted: 1 April 1997

\begin{abstract}
Changes in the three components of geomagnetic field are reported at the chain of ten geomagnetic observatories in India during an intense solar crochet that occurred at $1311 \mathrm{~h} 75^{\circ}$ EMT on 15 June 1991 and the subsequent sudden commencement (SSC) of geomagnetic storm at $1518 \mathrm{~h}$ on 17 June 1991. The solar flare effects (SFE) registered on the magnetograms appear to be an augmentation of the ionospheric current system existing at the start time of the flare. An equatorial enhancement in $\Delta H$ due to SFE is observed to be similar in nature to the latitudinal variation of SQ $(H)$ at low latitude. $\Delta Y$ registered the largest effect at 3. $6^{\circ}$ dip latitude at the fringe region of the electrojet. $\Delta Z$ had positive amplitudes at the equatorial stations and negative at stations north of Hyderabad. The SSC amplitude in the $H$ component is fairly constant with latitude, whereas the $Z$ component again showed larger positive excursions at stations within the electrojet belt. These results are discussed in terms of possible currents of internal and external origin. The changes in the $Y$ field strongly support the idea that meridional current at an equatorial electrojet station flows in the ionospheric dynamo, E.
\end{abstract}

\section{Introduction}

As is well known, solar flare effects (SFE) in the geomagnetic field at ground level represent changes in the ionospheric currents associated with the arrival of enhanced electromagnetic radiations from the Sun. Sudden commencements (SSC) of geomagnetic storms represent effects due to the ionised plasma cloud from

Correspondence to: D. R. K. Rao

*Presently at: School of Physics, University of New South Wales, Sydney, Australia the Sun following solar flares or from solar coronal holes.

The first observations of the simultaneous occurrence of a solar flare and the crochet in magnetic field related to the event of 1 September 1859 were reported by Carrington (1859) and Hodgson (1859). A comprehensive study of the SFE was made by McNish (1937), who examined the magnetograms from a large number of observatories to show that the effect of the flare on the magnetograms was the augmentation of the field values at the time of the flare. Nagata (1952) found an abnormally large effect of the solar flares on the geomagnetic $H$ field at Huancayo compared to two other stations at Kakioka and Watheroo. Forbush and Casaverde (1961) showed that the enhancement of SFE in $H$ at Peruvian stations varied in a manner similar to the enhancement of the SQ range of $H$ at equatorial latitudes. Rastogi et al. (1965) showed that the equatorial enhancement of SFE in $H$ was more pronounced in the American than in Indian longitudes, corresponding to the longitudinal variation of equatorial electrojet current itself. Srivastava (1974) seems to have been the first to describe the effect of solar flare on $D, H$ and $Z$ fields at Indian observatories. Rastogi et al. (1975) showed that some of the abnormal features of SFE in $H$ were due to a partial counter electrojet at the start time of the solar flare. Rastogi (1996a) described the results of an extensive study of SFE in $H$ and $D$ at the equatorial station Annamalainagar over the period 1967-1976. During the normal electrojet period a solar flare produced a positive change in $H$, a negative change in $Y$ and a negative change in $Z$. The effect on $\Delta Y$ (negative) increased linearly with increasing value of $\Delta H$. This suggested that the SFE on all the three components of the geomagnetic field were plainly the augmentation of the ionospheric current over the station.

The SSC of a magnetic storm is very clearly seen at temperate and low latitudes all over the world simultaneously to within a few seconds, and signifies an abrupt increase worldwide in the horizontal geomagnetic field 


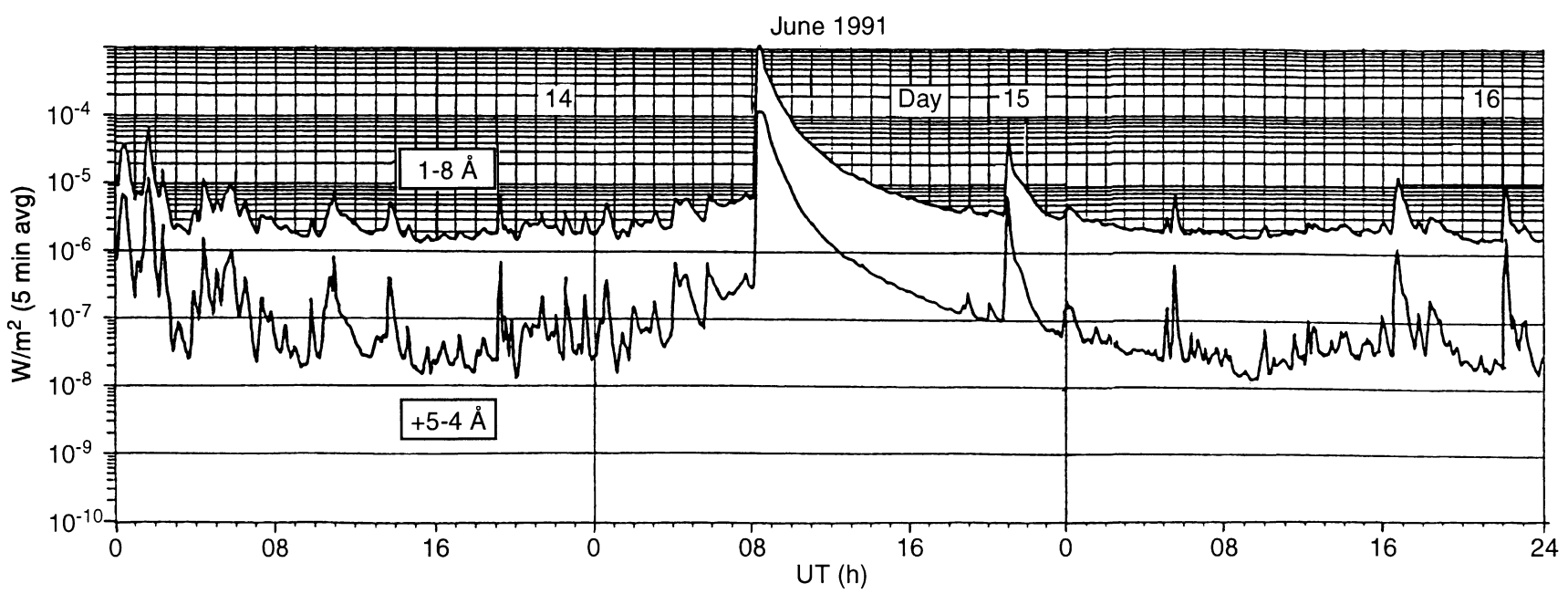

Fig. 1. Variation in solar X-ray flux within 0.5-4 and 1-8 A ranges during 14-16 June 1991 by instruments aboard the GOES satellite

$H$ and with associated sudden changes in declination $D$ and vertical intensity $Z$. The amplitude of SSC in $D$ depends on local time and season, whereas $\operatorname{SSC}(Z)$ depends on the location of the observing station. Latitudinal and longitudinal characteristics of the SSC $(H)$ have been dealt with by many researchers (e.g. Sugiura, 1953; Forbush and Casaverde, 1961; Rastogi et al., 1964, etc.).

These two phenomena, having distinctively different characteristics, can be studied from registrations in a suitable network of geomagnetic observatories to understand the ionospheric current systems during the events. India has a unique set of geomagnetic observatories spanning the latitudes of the magnetic equator and the SQ focus in a region of the world where the geomagnetic and geographic meridian planes are least separated. Taking advantage of this, we aim here to focus on some of the aspects of an SFE and associated SSC and their related changes in the ionospheric conductivities and electric fields.

\section{Event selection and presentation}

\subsection{SFE on 15 June 1991}

The Holloman observatory reported a type-3E optical solar flare on 15 June 1991 with a duration of $29 \mathrm{~min}$ starting at 0813 UT. The Wroclaw observatory reported a $H \alpha$ surge between 0820-0831 UT. The Ondrejov observatory reported a burst of decimeter and meter radio waves starting at $0813.5 \mathrm{UT}$ and ending at 1032.1 UT. Type-II radio bursts were reported at the Potsdam, San Vito and Wissenau observatories. The GOES satellite recorded beautiful bursts of solar X-ray radiations in the $0.5-4$ and $1-8 \AA$ ranges on 15 June 1991 , reproduced in Fig. 1 (Solar Geophysical Data bulletin $578 \mathrm{Pt}$. II). It is to be noted that the X-ray flux started increasing slowly after about $01 \mathrm{UT}$, and after $02 \mathrm{UT}$ it changed into a strong burst, increasing the flux after 08 UT by over two orders of magnitude. The flux had returned to its pre-flare value only by about $16 \mathrm{UT}$.

An abnormally large geomagnetic crochet (SFE) was registered at the Indian geomagnetic observatories at $1311 \mathrm{~h} 75^{\circ}$ EMT (0811 UT) on 15 June 1991. A large SSC followed this crochet on 17 June 1991 at $1518 \mathrm{~h}$, almost $50 \mathrm{~h}$ later. The geographic and geomagnetic coordinates of the Indian geomagnetic observatories, operational during June 1991, are given in Table 1; station codes are also included. The chain of stations whose magnetograms are used for the study all lie in more or less the same longitudinal sectors, barring Shillong, which is about $15^{\circ}$ further east of this sector.

Figure 2 shows the daily variations in $H, Y$ ( $Y$ is the Eastward component of the field computed from $H$ and $D$ ) at different stations (1) on the flare day 15 June 1991
Table 1. Geographic and geomagnetic coordinates of Indian geomagnetic observatories operating during 1991

\begin{tabular}{|c|c|c|c|c|c|c|}
\hline \multirow[t]{2}{*}{ station } & \multirow[t]{2}{*}{ code } & \multicolumn{2}{|c|}{ geographic } & \multicolumn{2}{|c|}{ geomagnetic } & \multirow{2}{*}{$\begin{array}{l}\text { dip } \\
\text { angle }\end{array}$} \\
\hline & & lat. $\mathrm{N}$ & long. E & lat. $\mathrm{N}$ & long. E & \\
\hline Trivandrum & TRD & 8.48 & 76.97 & -1.2 & 146.4 & 0.6 \\
\hline Ettaiyapuram & ETT & 9.17 & 78.00 & 0.6 & 147.5 & 2.2 \\
\hline Kodaikanal & KOD & 10.23 & 77.47 & 0.6 & 147.1 & 4.7 \\
\hline Annamalainagar & ANN & 11.37 & 79.68 & 1.4 & 149.4 & 7.1 \\
\hline Hyderabad & HYB & 17.42 & 78.55 & 7.6 & 148.4 & 21.8 \\
\hline Alibag & $\mathrm{ABG}$ & 18.62 & 72.87 & 9.5 & 143.6 & 25.4 \\
\hline Ujjain & UJJ & 23.18 & 75.78 & 13.5 & 147.0 & 33.9 \\
\hline Shillong & SHL & 25.57 & 91.88 & 14.6 & 162.4 & 45.9 \\
\hline Gulmarg & GUL & 34.08 & 74.40 & 24.5 & 147.2 & 50.1 \\
\hline
\end{tabular}



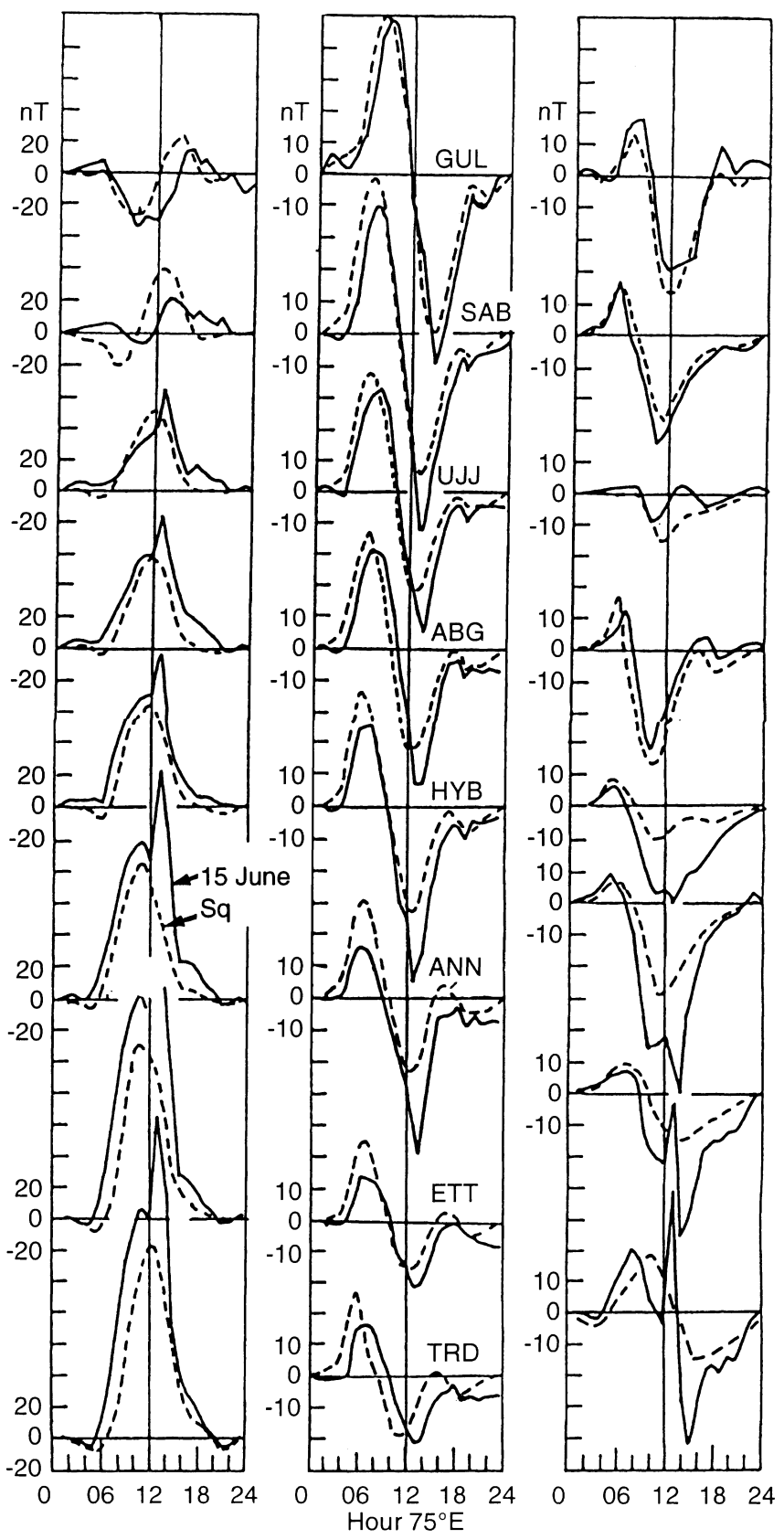

Fig. 2. The variations in the geomagnetic field $H$ (left panel), $Y$ (middle panel) and $Z$ (right panel) at the Indian observatories averaged on five international quiet days of June 1991 (dashed lines); individual day 15 June 1991 (full lines). All curves constructed from hourly mean values

and (2) averaged over the five international quiet days of June 1991 (henceforth denoted SQ) corrected for any daily inequalities. These curves are drawn through the hourly mean data points.

The variations in $H, Y$ and $Z$ fields at the chain of geomagnetic observatories along the India-Russia sector have been described by Patil et al. (1983) and by Rastogi (1996b). It is to be noted from the Fig. 2 that on quiet days the amplitude of $\Delta H$ decreased progressively from Trivandrum (TRD) to Gulmarg (GUL). Absence of a clear diurnal variation pattern at GUL and near equal magnitudes of the pre-noon and post-noon amplitude suggest that the SQ focus on average may be located in the vicinity of GUL during this month. The daily variation in $\Delta Y$ shows a positive peak in the morning and minimum at noon at all stations, including the electrojet stations, suggesting a well-developed vortex structure of the current system typical of local summer months. The daily variation in $\Delta Z$ shows a minimum around noon, a characteristic of northern-hemisphere stations. The daily range of $\Delta Z$ shows a maximum at Annamalainagar (ANN), which is situated at a latitude of largest gradient of $\Delta H$ within the equatorial electrojet belt.

Referring to the variations in the $H$ field on 15 June 1991, drawn with full lines, it is to be noted that $\Delta H$ at all low-latitude stations TRD to Alibag (ABG) started increasing earlier in the morning on the flare day and that throughout this day $\Delta H$ was larger than the average SQ values. The value of $\Delta$ at $1130 \mathrm{~h}$ at Ettaiyapuram (ETT) was $110 \mathrm{nT}$ on SQ days and $140 \mathrm{nT}$ on 15 June 1991. Similarly, at Hyderabad (HYB) $\Delta H$ was $65 \mathrm{nT}$ on SQ days and $70 \mathrm{nT}$ on 15 June 1991. Even the hourly mean value of $\Delta H$ at $13.5 \mathrm{~h}$ shot up to a value of $206 \mathrm{nT}$ from its 12.5 -h value of $140 \mathrm{nT}$. A similarly large increase in hourly mean $\Delta H$ at $13.5 \mathrm{~h}$ is seen at all stations up to Ujjain (UJJ). No large increase in $\Delta H$ at $13.5 \mathrm{~h}$ is evidenced at Sabha wala, (SAB) and GUL due to its proximity to the SQ focus, where the currents north and south of the station cancel the effect on $\Delta H$.

Regarding the variations in the $Z$ field ignoring the individual value at $13.5 \mathrm{~h}$ at TRD and ANN, one would conclude a large increase in electrojet current on 15 June 1991 compared to that on SQ days; these effects are again largest at ANN and HYB. What seems to be an abnormal feature is the sudden large positive increase at $13.5 \mathrm{~h}$ at TRD and ETT [Kodaikanal (KOD) data on $Z$ were not available on 15 June 1991].

The magnetogram traces at different stations were reorganised to study the effect of the solar flare on the individual components $H, Y$ and $Z$ at stations extending from the equatorial location of TRD to a station in the vicinity of SQ focus, GUL, and are shown in a, b and c of Fig. 3, respectively. These are the tracings of actual magnetograms, and these have different scale values. The numbers indicate the magnitude of SFE on the particular component.

$\Delta H$ at TRD shows a sudden increase in $H$ at $1311 \mathrm{~h}$ EMT due to SFE. The amplitude of $187 \mathrm{nT}$ is unusually large and is one of the largest flare effects recorded at TRD. The $H$ recordings at ETT went off the scale, but by comparison with the time-profile of $\Delta H$ at neighbouring station TRD an amplitude of $176 \mathrm{nT}$ was estimated. The amplitude of SFE in $H$ decreased progressively with increasing latitude of the station and became quite small ( $-6 \mathrm{nT})$ at GUL.

The $\Delta Y$ trace at all stations showed a negative excursion due to SFE. Examining the daily variations of $\Delta Y$, it can be seen that the flare occurred immediately after noon $\left(1311 \mathrm{~h} 75^{\circ}\right.$ EMT) when $\Delta Y$ reached its diurnal minimum value. An abnormally large $Y$, equal to $-67 \mathrm{nT}$, was recorded at ANN. The amplitude of $\Delta Y$ 
sfe-Y
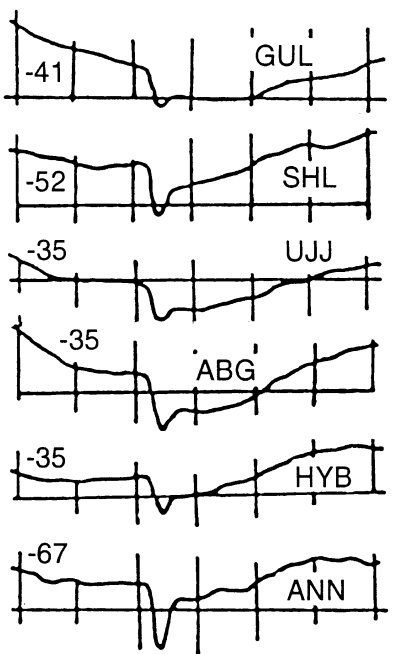

$-19$
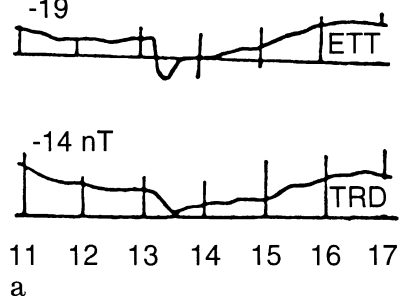

15 June 1991

sfe-H
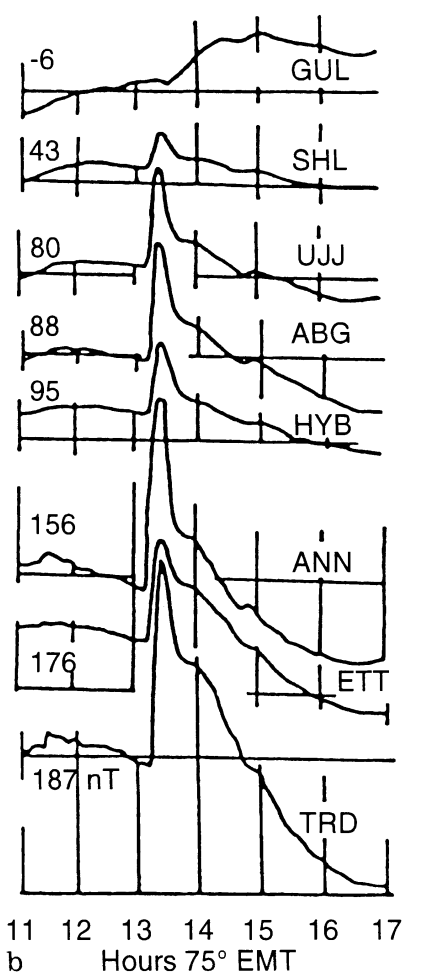

b Hours $75^{\circ}$ EMT

at ETT $(-19 \mathrm{nT})$ was nearly the same as that at TRD $(-14 \mathrm{nT})$, which is closest to the dip equator.

The magnetograms showing $Z$ at different stations present unexpected registrations. The SFE was very large in amplitude, equal to $+180 \mathrm{nT}$ at TRD, and this is found to decrease rapidly with increasing latitude, decreasing to $-4 \mathrm{nT}$ at HYB. At stations north of HYB, SFE ( $Z$ ) was significantly negative, being around $-30 \mathrm{nT}$. This positive SFE $(Z)$ with a strong equatorial enhancement within the electrojet belt is a phenomenon which requires further examination.

In order to understand the SFE in $H, Y$ and $Z$ the deviations of these components just before the start of the flare with respect to the $0000 \mathrm{~h}$ value on the same day were also noted and referred to as the pre-flare values $\Delta H_{0}, \Delta Y_{0}$ and $\Delta Z_{0}$.

Figure 4 shows the latitudinal variations of (1) preflare values, $\Delta H_{0}, \Delta Y_{0}$ and $\Delta Z_{0}$, (2) enhancements due to flare on the components $\Delta H_{\mathrm{SFE}}, \Delta Y_{\mathrm{SFE}}$ and $\Delta Z_{\mathrm{SFE}}$ and (3) the ratios $\Delta H_{\mathrm{SFE}} / \Delta H_{0}$ and $\Delta Y_{\mathrm{SFE}} / \Delta Y_{0}$ for the solar flare at $1311 \mathrm{~h}\left(75^{\circ} \mathrm{EMT}\right)$ on 15 June 1991.

The SFE in $H$ is seen to increase in a fashion very similar to that of pre-flare $\Delta H_{0}$. The ratio of $\Delta H_{\mathrm{SFE}} / \Delta H_{0}$ at all stations except GUL, a station very close to SQ focus, varied from about 1.5 to 2.0 .

The eastward field $\Delta Y_{0}$ at the time of flare onset varied between -15 and $-40 \mathrm{nT}$ at different stations, with a general increase in the negative amplitude with latitude. The solar flare effect, $\Delta Y_{\mathrm{SFE}}$ varied between -14 and $-70 \mathrm{nT}$, showing a peak around $10^{\circ}$ dip.

The latitudinal variation of $\Delta Z_{0}$ showed a very low value at the equator and a negative value around $-40 \mathrm{nT}$ at other latitudes. There is a suggestion of a

sfe-Z
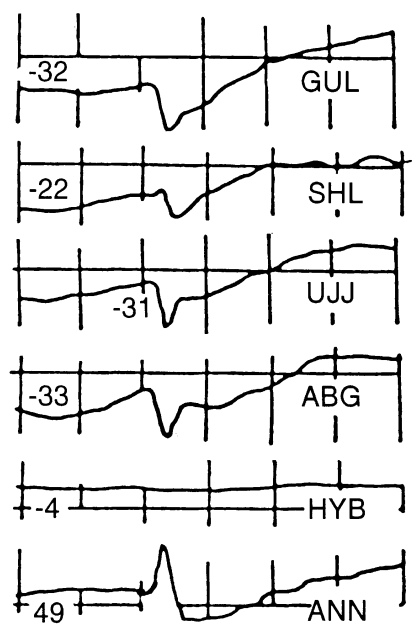

Fig. 3a-c. The magnetogram tracings at Indian Observatories showing the SFEs on a $Y$, b $H$ and c $Z$ components due to the flare at $1311 \mathrm{~h} 75^{\circ}$ EMT on 15 June 1991. The amplitudes of SFE at each of the stations for the three components of geomagnetic field are indicated

maximum around ANN, a station near the fringe of the electrojet belt. The $\Delta Z$ due to SFE showed almost similar values at stations north of HYB, but abnormally large positive deviations are noted at the equatorial stations TRD, ETT and ANN.

Figure 5 shows the current vectors which are computed as the resultant magnitudes of the two orthogonal horizontal field vectors ( $\Delta H$ and $\Delta Y$ amplitudes of SFE with respect to pre-flare values) and rotating the same $90^{\circ}$ clockwise. It is to be noted that the current vectors due to both the SQ as well as to the crochet are practically in the same direction at low latitudes of the Indian subcontinent, although the magnitudes of the vectors are different, as expected.

\subsection{SSC on 17 June 1991}

Figure 6 reproduces the magnetograms of the different stations in India showing the SSC effects on $H, Y$ and $Z$ components at $1518 \mathrm{~h} 75^{\circ}$ EMT on 17 June 1991. Again, these are tracings of magnetograms with different scale values. The magnitude of SSC in $\mathrm{nT}$ is indicated on the tracings. The latitudinal variations in the pre-SSC values of the three components, viz. $\Delta H_{0}, \Delta Y_{0}$ and $\Delta Z_{0}$ as well as SSC amplitudes in these components are shown in Fig. 7.

The pre-SSC $\Delta H_{0}$ showed a monotonous increase with decreasing latitude. No significant equatorial enhancement of $\Delta H_{0}$ was evident, as the SSC occurred in the late afternoon hours when the electrojet currents are greatly reduced. The SSC amplitude in $H$ was $60 \mathrm{nT}$ at TRD and almost of the same amplitude at other 


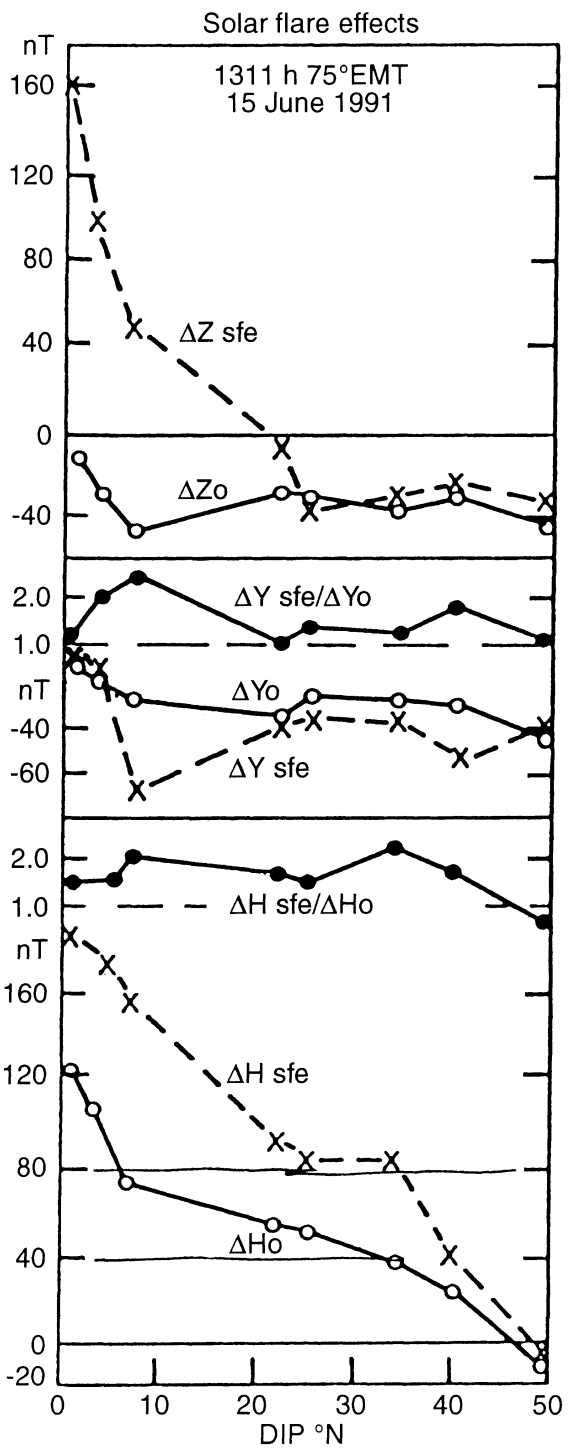

Fig. 4. Latitudinal variations in the amplitudes in the three components of the geomagnetic field during the flare $\left(\Delta Y_{\mathrm{SFE}}, \Delta H_{\mathrm{SFE}}\right.$ and $\left.\Delta Z_{\mathrm{SFE}}\right)$ and pre-flare SQ $\left(\Delta Y_{0}, \Delta H_{0}\right.$ and $\left.\Delta Z_{0}\right)$. Also the ratios of the amplitudes in $Y$ and $H$ components at SFE and pre-SFE times with latitudes are shown

stations, indicating again the non-existence of equatorial enhancement which is the characteristic feature of midday SSC events at low latitudes (Rastogi, 1993a). The SSC amplitude in $\Delta Y$ showed a uniform latitudinal variation with an indication of larger deviation at ANN situated at the periphery of the electrojet. The SSC signature of the $\Delta Z$ field showed a positive excursion at the equatorial stations and a negative deviation at stations north of HYB. This feature in $\Delta Z$ is nearly the same as that of the SFE.

\section{Discussion}

Before summarising and discussing the observations of solar flare and sudden commencements on the three components of the geomagnetic field, it is essential to

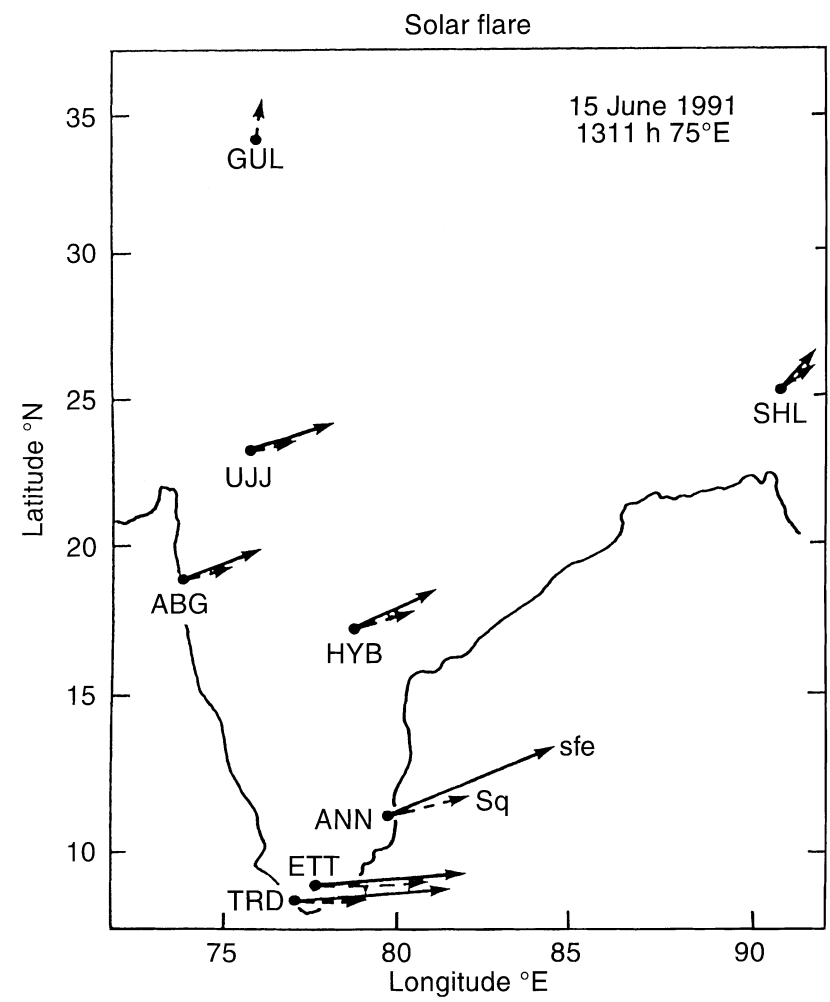

Fig. 5. Equivalent ionospheric current vectors (1) solar flare effect (continuous line) and (2) pre-flare SQ (dashed line), at Indian observatories

seek the origins of these phenomena. The SFE are associated with the arrival of a sudden increase of electromagnetic radiations from the Sun, which, while traversing the ionosphere, generate additional ionisations mainly in the $\mathrm{E}$, partially in the $\mathrm{D}$ and sometimes in the $\mathrm{F}$ region. The SSC of a magnetic storm indicates the arrival of a dense plasma cloud consisting of charged particles from the Sun, generally a few tens of hours after the occurrence of the solar flare. These clouds are stopped at the magnetopause when the dynamic pressure of the charged particles is balanced by the magnetic pressure of the Earth's magnetic field and the magnetosphere is compressed, causing a sudden increase in $H$ at stations around the world on the dayside as well as the nightside.

The results of SFE at the Indian stations indicate that the disturbance vectors of the solar flare were almost in the same direction as the pre-SFE (SQ) vector just before the start of the event. Volland and Taubenheim (1958), while examining SFE at the European stations between latitudes of $10^{\circ}$ and $60^{\circ}$ North have shown an angular difference of $15^{\circ}-30^{\circ}$ between the SQ and SFE vectors. Veldkamp and Sabben (1960) also detected differences between SFE and SQ vectors at European stations during the flare on 23 March 1958. Sabben (1968), after re-examining the current systems due to SFE during the period 1959-1961, concluded that the SFE can be considered as a temporary augmentation of the daily variation of the magnetic field based on the comparison of the disturbance vectors of the SFE and 

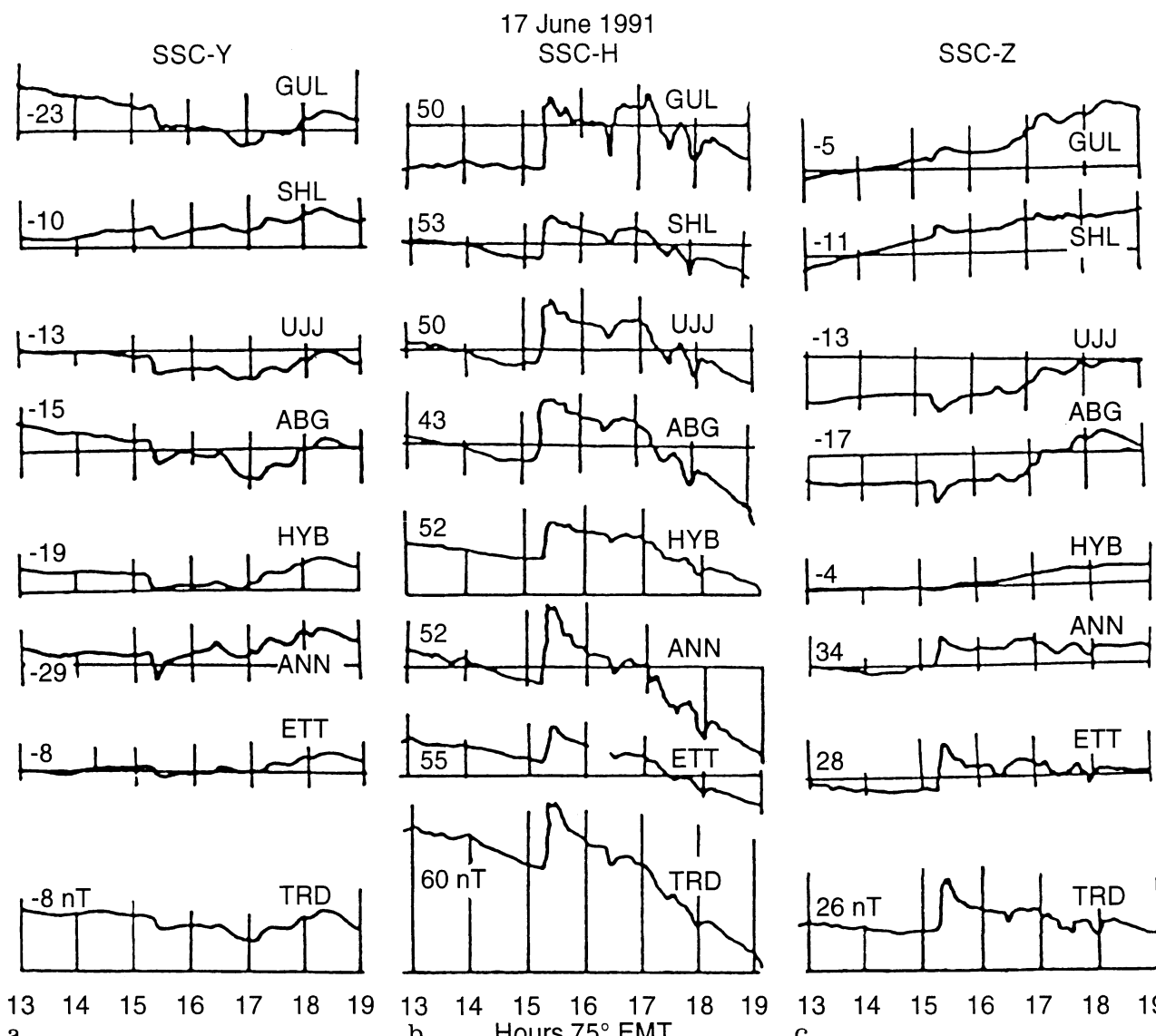

Fig. 6. Magnetogram tracings from Indian Observatories showing signatures of storm sudden commencement (SSC) at $1518 \mathrm{~h}$ $75^{\circ}$ EMT on 17 June 1991. The

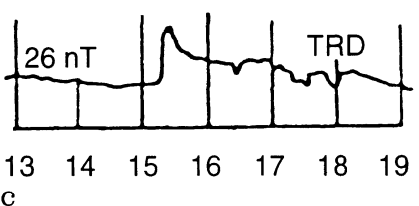
amplitudes of SSC at each of the stations for the three components of the geomagnetic field in $\mathrm{nT}$ are indicated

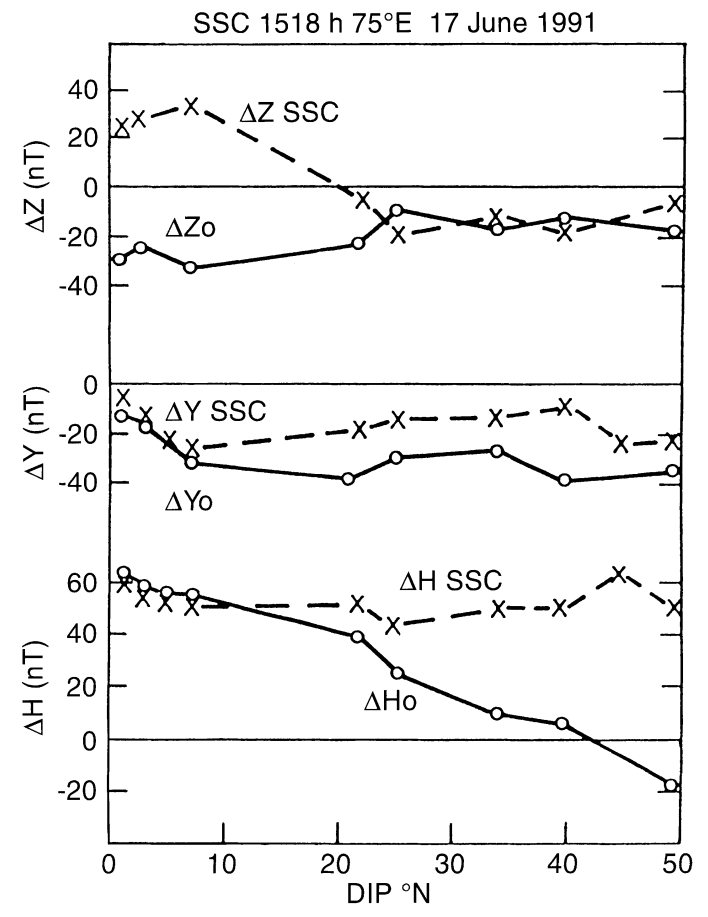

Fig. 7. Latitudinal variations in the amplitudes of $\operatorname{SSC}\left(\Delta H_{\mathrm{SSC}}\right.$, $\Delta Y_{\mathrm{SSC}}$, and $\left.\Delta Z_{\mathrm{SSC}}\right)$ at $1518 \mathrm{~h} 75^{\circ} \mathrm{EMT}$ on $17 \mathrm{June} 1991$ and pre-SSC $\left(\Delta H_{0}, \Delta Y_{0}\right.$ and $\left.\Delta Z_{0}\right)$ in the three components of the field

SQ currents at individual stations and their distribution over the world. The horizontal equivalent current vectors for both SFE and pre-SFE (SQ) disturbances over the Indian stations situated within a narrow longitude sector, shown in Fig. 4, have nearly the same directions, thereby indicating (within the limits of time resolution) the augmentation of the integrated effects on the ground in the north-south and east-west fields.

One of the interesting observations of the flare event here is the existence of significant eastward magnetic field within the electrojet region on a normal day and its effect on the SFE that is noticed to be proportional to the pre-flare condition over wide range of latitudes (Fig. 3). The close similarities of the latitudinal profiles of SFE and SQ amplitudes (although substantial enhancement of the flare vector at ANN is noticed over that of SQ) at low-latitude stations in India suggest that the SQ variation in the $Y$ field at equatorial stations are due to currents in the $\mathrm{E}$ region of the ionosphere, as in the case of the $H$ field.

The present result of enhanced amplitudes of $\Delta H_{\mathrm{SFE}}$ at stations under the influence of equatorial electrojet, and more importantly the large positive excursion of $\Delta Z$ at stations TRD, ETT, KOD and ANN is a marked feature. The ionospheric current models of the equatorial electrojet envisage that the enhanced eastward electric currents are expected to give rise to a minimum of the vertical component of the geomagnetic field at latitudes in the vicinity of the central axis of the 
electrojet and should have maxima at the periphery. Thus, the observational fact of large positive excursions in $\Delta Z$ at electrojet stations may not be the direct effect of the equatorial electrojet current.

Srivastava (1975) reported that the solar flare of 3 May 1973 at $1330 \mathrm{~h} 75^{\circ}$ EMT had produced positive $\Delta Z$ at all stations in India, except that at $A B G \Delta Z$ was negative. The author suggested that $\Delta Z$ at $A B G$ was apparently contaminated by a coastal effect due to oceanic-induced electric currents.

Veldekamp and Sabben (1960) suggested that there were differential movements of the vortices in the current systems due to SQ and SFE. Rikitake and Yukutake (1962) and Greenfield and Venkateswaran (1967) suggested the phenomenon of 'self induction' to explain the observations. Roy $(1977,1979)$ introduced the idea of mutual induction between the E- and Dlayers during solar flares. However, the observations of abnormal signatures of $\Delta Z$ at the chain of equatorial stations in India, probably described for the first time here, elude any clear explanation.

It is even more difficult to explain the latitudinal variation of SSC amplitude in $\Delta Z$ (shown as $\Delta Z$ SSC in Fig. 6). The variations of $\Delta Z$ (SSC) closely follow that of $\Delta Z$ (SFE) in the sense that positive amplitudes at the stations under the influence of the equatorial electrojet near zero amplitude at HYB and negative signatures at stations north of this station.

Obayashi and Jacobs (1957) studied the SSC in $X, Y$ and $Z$ components at a large number of stations round the world, and showed that the amplitudes of SSC in $X$ and $Y$ vary in a regular fashion with geomagnetic latitude. The SSC in $Z$ showed very irregular distribution from place to place. They suggested this irregular behaviour was due to the effect of the induced currents inside the Earth, where the distribution of electrical conductivity may be considerably heterogeneous.

Ivanov (1964) has displayed a map of geomagnetic stations that have registered positive and negative signs of $\Delta Z$ (SSC) employing International Geophysical Year (IGY) data of northern-hemisphere observatories. The author also reported several stations (from both the hemispheres) where the sign of SSC in $\Delta Z$ is sometimes positive, and negative other times. As per the theoretical consideration of Parker (1962), the sign of $\Delta Z$ (SSC) is negative (positive) in the northern (southern) hemisphere. If it were otherwise, it could be considered as anomalous and this behaviour would be the result of peculiarities of the current system induced in the Earth's upper mantle (Ivanov, 1964). If the induced currents are responsible for the sign changes of the $\Delta Z$ (SSC), it is reasonable to assume that all the short-period variations (SSCs, SIs, SFEs and bays of comparable period) must show the same anomalous behaviour at the Indian observatories consistently. Srivastava and Prasad (1974) have noted that during solar flare of 3 May 1973 the effects in $H$ and $D$ at ABG and HYB were comparable, whereas in $Z$ there was negative amplitude at the former and positive at the latter station. They have attributed the negative signature at $\mathrm{ABG}$ to the abnormal induction effects associated with Deccan traps and also to the oceanic-induced electric currents. Nityananda et al. (1977) have studied electromagnetic induction effects within the Earth at short-period fluctuations (SSC and bay events) at the Indian observatories. They have explained the variations in the $Z$ component as due to the effects of channelling of induced currents through the Palk Straits at the Southern tip of the Indian Peninsula.

It may be recalled that the first model by Chapman (1951) envisaged a maximum of $\Delta H$ at the equator and a maximum negative excursion of $\Delta Z$ at the northern fringe region of the electrojet. The observed $\Delta Z$ at any station represents the gradient of the east-west current around the station. The complex structures in $\Delta Z$ have been well demonstrated by the changes in $\Delta H$ during partial counter electrojet events (Rastogi et al., 1992; Rastogi, 1993b), which are produced as a resultant of two currents at the height of peak E-region ionisation $(106 \mathrm{~km})$ and at the height of the largest Hall polarization field $(100 \mathrm{~km})$. It is suggested here that the abnormal features of $\Delta Z$ at equatorial stations may also possibly be due to the distortions produced in the altitude profile of the ionospheric current at low latitudes, depending upon the spectrum of the solarflare radiations. Even if the solar-flare currents produced are uniform in altitude, a different latitude gradient of the integrated currents may be generated which would distort the amplitude and sign of the variations in the vertical field. Some of these features can be checked with SFE during counter electrojet conditions and by studying SFE at a latitudinal chain of stations north and south of the magnetic equator.

Acknowledgements. The authors are thankful to B. P. Singh, Mita Rajaram and M. Roy of the Indian Institute of Geomagnetism, Colaba, Mumbai, for discussions and suggestions. Sincere thanks are also due to R. J. Stening for valuable advice and suggestions during the course of revision of the original manuscript.

Topical Editor D. Alcaydé thanks T. Araki and R. J. Stening for their help in evaluating this paper.

\section{References}

Carrington, R. C., Description of a singular appearance seen in the sun on Sept. 1, 1859, Mon. Not. R. Astron. Soc., 20, 13, 1859.

Chapman, S., The equatorial electrojet as detected from the abnormal electric current distribution above Huancaya, Peru and elsewhere, Arch. Meteorol. Geophys. Bioclimatol., 4, 368390, 1951.

Forbush, S. E., and M. Casaverde, Equatorial electrojet in Peru, CIW Publ. 620, Washington DC, 1961.

Greenfield, S. M., and S. V. Venkateswaran, The vertical structure of dynamo winds deduced from geomagnetic variations associated with solar flares, in Proc. Birkeland Symp. Aurora and magnetic storms, Eds. A. Egeland and J. Holtet, C.N.R.S., Paris, pp: 403-411 1967.

Hodgson, R., On a curious appearance seen in the sun, Mon. Not. R. Astron. Soc., 20, 15, 1859.

Ivanov, K. G., Map of the distribution of the sign of the $\mathbf{Z}$ component of the SSC field over the Earth's surface, Geomagn. Aeron., 4, 629-630, 1964.

McNish, A. G., Terrestrial, magnetic and ionospheric effects associated with bright chromospheric eruptions, Terr. Magn. Atmos. Electr., 42, 109-122, 1937.

Nagata, T., Characteristics of the solar flare effects (Sqa) on geomagnetic field at Huancayo (Peru) and at Kakioka (Japan), J. Geophys. Res., 57, 1-14, 1952. 
Nityananda, N., A. K. Agarwal, and B. P. Singh, Induction at short periods in the horizontal field variations in the Indian Peninsula, Phys. Earth Planet. Inter., 15, 5-9, 1977.

Obayashi, T., and J. A. Jacobs, Sudden commencements of magnetic storms and atmospheric dynamo action, J. Geophys. Res., 62, 589-616, 1957.

Parker, E. N., Dynamics of geomagnetic storm, Space Sci. Rev., 1, 62-99, 1962.

Patil, A., B. R. Arora, and R. G. Rastogi, Daily variations of the geomagnetic field near the focus of SQ current system in Indian longitude, Proc. Ind. Acad. Sci., 92, 239-245, 1983.

Rastogi, R. G., Longitudinal variation of sudden commencement of geomagnetic storm at equatorial stations, J. Geophys. Res., 98, 15411-15416, 1993a.

Rastogi, R. G., Complexities of ionospheric current system at low latitudes, Ann. Geophysicae, 11, 273-282, 1993b.

Rastogi, R. G., Solar flare effects on zonal and meridional currents at the equatorial electrojet station, Annamalainagar, J. Atmos. Terr. Phys., 58, 1413-1420, 1996a.

Rastogi, R. G., Zonal and meridional ionospheric currents in Central Asian sector, Ind. J. Radio Space Phys., 25, 291-299, 1996b.

Rastogi, R. G., N. D. Kaushika, and N. B. Trivedi, Some relations between the sudden commencements at the equatorial electrojet, J. Atmos. Terr. Phys., 26, 771-776, 1964.

Rastogi, R. G., N. D. Kaushika, and N. B. Trivedi, Solar flare crochet and sudden commencement in $\mathrm{H}$ within the equatorial electrojet region. J. Atmos. Terr. Phys., 27, 663-668, 1965.
Rastogi, R. G., M. R. Deshpande and N. S. Sastri, Solar flare effect in equatorial counter electrojet currents, Nature, 258(5532), 218-219, 1975

Rastogi, R. G., G. K. Rangarajan, and V. V. Somayajulu, Complexities of counter electrojet currents in Indian zone, Ind. J. Radio Space Phys., 21, 89-96, 1992.

Rikitake, T., and Y. Yukutaka, A theory of s.f.e. current system, $J$. Atmos. Terr. Phys., 24, 93-106, 1962.

Roy, M., Mutual induction between the E- and the D-layers of the ionosphere during a solar flare, J. Atmos. Terr. Phys., 39, 221227, 1977.

Roy, M., A two-layer model for the geomagnetic crochet, J. Atmos. Terr. Phys., 41, 225-229, 1979.

Sabben, D. van, Solar flare effects and simultaneous magnetic daily variation, 1959-1961. J. Atmos. Terr. Phys., 30, 1641-1648, 1968.

Srivastava, B. J., The geomagnetic solar flare effect of 3 May 1973 at Indian stations and its dependence on the counter electrojet, J. Atmos. Terr. Phys., 36, 1571-1575, 1974.

Srivastava, B. J., and S. N. Prasad, Role of the Deccan volcanics in the reversal of short period geomagnetic Z-variations at Alibag, Phys. Earth Planet. Inter., 9, 157-160, 1974.

Sugiura, M., The solar diurnal variation in the amplitude of sudden commencements of magnetic storms at the geomagnetic equator, J. Geophys. Res., 58, 558-559, 1953.

Veldkamp, J., and D. van Sabben, On the current system of solar flare effects, J. Atmos. Terr. Phys., 18, 192-202, 1960.

Volland, H., and J. Taubenheim, On the ionospheric current system of the geomagnetic solar flare effect (sfe), J. Atmos. Terr. Phys., 12, 258-260, 1958. 